\title{
TEXCOCO F2016, NUEVA VARIEDAD DE TRIGO HARINERO PARA SIEMBRAS DE SECANO EN MÉXICO
}

\section{TEXCOCO F2016, A NEW WHEAT VARIETY FOR PLANTING UNDER RAINFED CONDITIONS IN MEXICO}

\author{
Héctor E. Villaseñor-Mir ${ }^{1}$, Julio Huerta-Espino ${ }^{1}$, María F. Rodríguez-García ${ }^{1}$, René \\ Hortelano-Santa Rosa', Eliel Martínez-Cruz' ${ }^{1}$, Eduardo Espitia-Rangel', Ernesto Solís- \\ Moya $^{2}$, Leodegario Osorio-Alcaláa ${ }^{3}$, Luis A. Mariscal-Amaro ${ }^{2}$ y Luis M. Macías-Valdés ${ }^{4}$
}

\begin{abstract}
'Instituto Nacional de Investigaciones Forestales, Agrícolas y Pecuarias (INIFAP), Campo Experimental Valle de México, Coatlinchán, Texcoco, Estado de México, México. ${ }^{2}$ INIFAP, Campo Experimental Bajío, Celaya, Guanajuato, México. ${ }^{3}$ INIFAP, Campo Experimental Valles Centrales de Oaxaca, Santo Domingo Barrio Bajo, Etla, Oaxaca, México. ${ }^{4}$ INIFAP, Campo Experimental Pabellón, Pabellón de Arteaga, Aguascalientes, México.

*Autor de correspondencia (rodriguez.maria@inifap.gob.mx)
\end{abstract}

El trigo harinero (Triticum aestivum L.) es el cereal de mayor importancia mundial después del maíz (Zea mays L.); la producción mundial se destina principalmente para consumo humano (FAO, 2020). Diversos factores bióticos y abióticos reducen su producción; entre los factores bióticos, las enfermedades fungosas son las de mayor importancia (Beddow et al., 2015).

En trigo las enfermedades conocidas como royas, causadas por el género Puccinia, históricamente han causado pérdidas económicas importantes en México y en el mundo (Huerta et al., 2012). Estos hongos cambian su virulencia constantemente y generan nuevas razas fisiológicas que vencen la resistencia de las variedades en uso (Rodríguez-García et al., 2010). Es necesario disponer de nuevas variedades con la resistencia necesaria para hacer frente a las razas presentes y que además posean buenas características agronómicas y de calidad industrial.

Texcoco F2016 es resultado de la aplicación de los métodos de hibridación y selección en el Programa de Mejoramiento Genético de Trigo de Temporal del Instituto Nacional de Investigaciones Forestales, Agrícolas y Pecuarias (INIFAP). La cruza (TC080523) entre la línea GAVIA/ROM/3/PIRUL/GUI//TEMP/AGR y la variedad Juchi F2000 se realizó en el ciclo P-V/2008 en el Campo Experimental Valle de México (CEVAMEX) ubicado en Chapingo, Estado de México. La generación $F_{1}$ se avanzó masivamente en el Campo Experimental El Bajío (CEBAJ), ubicado en Celaya, Guanajuato. La $F_{2}$ se sembró en el CEVAMEX en el ciclo P-V/2009 y la población 20024 se cosechó en masa (OC). La población $F_{3}$ se evaluó en el CEBAJ en el ciclo 0-I/2009-2010 y la planta número $3(3 R)$ se cosechó individualmente. La $F_{4}$ se evaluó en el CEVAMEX en el ciclo P-V/2010 y se seleccionó la familia 40225, que se cosechó masivamente. La $F_{5}$ se sembró en el CEBAJ en el ciclo 0-I/2010-2011 y la familia 50105 se cosechó en masa (OR). En $F_{6}$ esta familia se sembró en el CEVAMEX durante el ciclo P-V/2011, donde se seleccionó la planta número 4 (4C), la que se cosechó de manera individual y se sembró como $F_{7}$ en el CEBAJ en el ciclo 0-I/2011-2012, donde se cosechó en masa (OR). La línea experimental que dio origen a Texcoco F2016 viene de la cruza GAVIA/ROM/3/PIRUL/GUI//TEMP/AGR/4/JUCHI y el pedigrí TC080523-0C-3R-0C-0R-4C-0R.

La línea experimental se evaluó durante cuatro años (2013 a 2016) en 61 ambientes en los estados de Oaxaca, Puebla, Tlaxcala, Hidalgo, México, Guanajuato, Aguascalientes, Zacatecas y Durango. Su rendimiento superó al de las variedades testigo (Náhuatl F2000, Rebeca F2000, Tlaxcala F2000, Triunfo F2004, Nana F2007 y Altiplano F2007) entre 19 y $54 \%$, ventaja que se mantuvo en ambientes favorables, intermedios y críticos de producción. Su ventaja fue más notoria en los ambientes donde prevalecen condiciones favorables para la incidencia de roya amarilla.

Texcoco F2016 es de hábito de primavera, de ciclo intermedio (días a madurez de 112 d en promedio ), con pigmentación antociánica del coleóptilo ausente o muy débil, su porte de planta es intermedio (altura promedio de $93 \mathrm{~cm}$ ) y es resistente al acame (Figura 1). Presenta una frecuencia alta de plantas con hoja bandera recurvada, su espigamiento es uniforme, con espigas de bordes paralelos, con poca serosidad durante el llenado de grano, coloreadas en madurez y de posición ligeramente curvada; su grano es de tamaño mediano, de color rojo, de consistencia dura y con coloración clara a la reacción al fenol.

La mayor ventaja de Texcoco F2016 sobre los testigos es su resistencia a roya amarilla (Puccinia striiformis f. sp. tritici), sobre todo ante las razas CMEX14.25, MEX14.141 


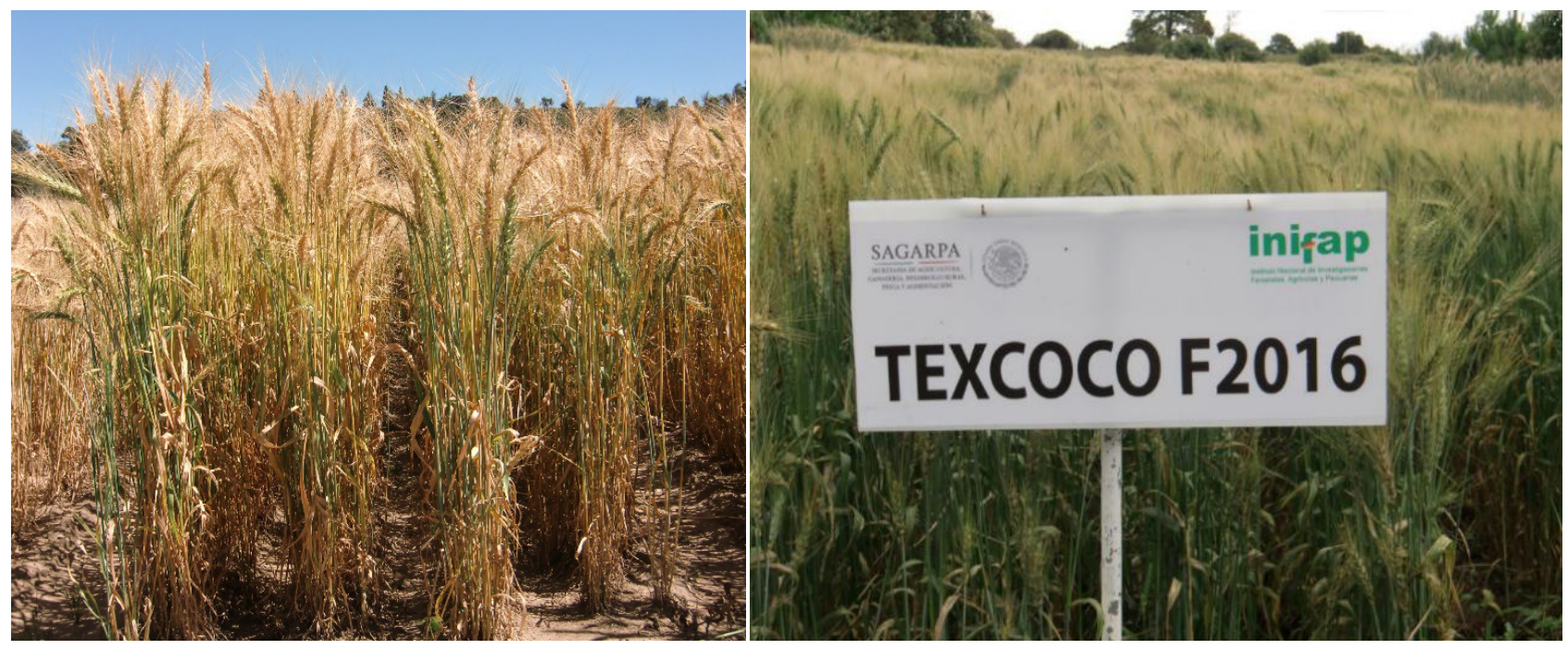

Figura 1. Porte de planta de Texcoco F2016 con resistencia a roya amarilla.

y MEX14.146, que en el verano de 2014 los volvieron de moderadamente susceptibles a susceptibles (Solís et al. 2016). Su respuesta se debe a los genes de resistencia de raza específica con efectos intermedios en plántula, que se manifiestan en planta adulta y que interactúan con los genes Yr18 y Yr29, ligados a la necrosis de la punta de la hoja (Ltn: leaf tip necrosis), carácter morfológico corroborado con los marcadores moleculares CSLV34b (Kolmer et al., 2008) y CsLV46b (Rosewarne et al., 2006). Es moderadamente resistente a roya de la hoja causada por Puccinia triticina E., con lecturas de 0 a $15 \%$ de infección, y basa su resistencia en los genes Lr1, Lr10 y $L r 17$ de raza específica, que confieren resistencia en todas las etapas de crecimiento; en planta adulta esa resistencia se debe al efecto de los genes $L r 34$ y $L r 46$, presencia que se determinó con los marcadores moleculares CsLV34b (Kolmer et al., 2008) y CsLV46G22 (Ponce-Molina et al., 2018).

Texcoco F2016 es tolerante al complejo de enfermedades foliares causadas por Zymoseptoria tritici, Z. nodorum, Phyrenophora tritici-repentis y Cochliobolus sativus; sus pérdidas en rendimiento fueron del $11 \%$ en comparación con Nana F2007, que presentó $36 \%$.

El grano de Texcoco F2016 es duro, lo que es deseable para evitar germinación en la espiga durante post-antesis. Con base en la fuerza de la masa, se clasificó como trigo de gluten fuerte $\left(\mathrm{W}>300 \times 10^{-4} \mathrm{~J}\right)$, adecuado para la panificación mecanizada. Su masa combinó fuerza y extensibilidad (valores de $\mathrm{PL}<1$ relación tenacidadextensibilidad), lo que permite mezclarlo con trigos tenaces o de gluten suave para adecuarlo a la repostería artesanal. Sus valores de W y PL le permiten alcanzar volumen de pan de $871 \mathrm{~cm}^{3}$ en promedio, lo que lo iguala a los mejores testigos (Altiplano F2007 y Tlaxcala F2000) (Villaseñor-Mir et al., 2005).

La nueva variedad Texcoco F2016 es resistente a roya amarilla, de buena calidad industrial, con buen comportamiento agronómico en siembras de secano con escasa presencia de lluvias $(<350 \mathrm{~mm})$, medio lluviosos (350 a $500 \mathrm{~mm}$ ) y lluviosos (> $500 \mathrm{~mm}$ ). Se recomienda para las zonas productoras de trigo de secano de Oaxaca, Puebla, Tlaxcala, Hidalgo, Estado de México, Guanajuato, Zacatecas y Durango.

Esta nueva variedad cuenta con el registro TRI-179090318 en el Catálogo Nacional de Variedades Vegetales del Servicio Nacional de Inspección y Certificación de Semillas y el Título de Obtentor No. 1929, otorgado en agosto de 2018. El programa de trigo del INIFAP-CEVAMEX resguarda y pone a disposición de los interesados las categorías de semilla original y básica de esta variedad.

\section{AGRADECIMIENTOS}

Al Fondo SAGARPA-CONACYT, por el financiamiento parcial del proyecto Núm. 146788: "Sistema de mejoramiento genético para generar variedades resistentes a royas, de alto rendimiento y alta calidad para una producción sustentable de trigo en México".

\section{BIBLIOGRAFÍA}

Beddow J. M., P. G. Pardey, Y. Chai, T. M. Hurley, D. J. Kriticos, H. J. Braun, ... and T. Yonow (2015) Research investment implications of shifts in the global geography of wheat stripe rust. Nature Plants 1:15132, http://doi.org/10.1038/nplants.2015.132 
FAO, Food and Agriculture Organization of the United Nations (2020) Perspectivas de Cosechas y Situación Alimentaria. Informe Trimestral Mundial No. 1. Marzo 2020. Food and Agriculture Organization of the United Nations. Roma, Italia. 48 p, https:// doi.org/10.4060/ca8032es

Huerta E. J., R. Torres G., M. F. Rodríguez G., H. E. Villaseñor M., S. G. Leyva M. y E. Solís M. (2012) Resistencia a roya amarilla (Puccinia striiformis f. sp. tritici) en variedades de trigo harinero (Triticum aestivum L.). Revista Mexicana de Ciencias Agrícolas 3:879891, https://doi.org/10.29312/remexca.v3i5.1381

Kolmer J. A., R. P. Singh, D. F. Garvin, L. Viccars, H. M. William, J. HuertaEspino, ... and E. S. Lagudah (2008) Analysis of the Lr34/Yr78 rust resistance region in wheat germplasm. Crop Science 48:18411852, https://doi.org/10.2135/cropsci2007.08.0474

Ponce-Molina L. J., J. Huerta-Espino, R. P. Singh, B. R. Basnet, G. Alvarado, M. S. Randhawa, ... and J. J. García-Zavala (2018) Characterization of leaf rust and stripe rust resistance in spring wheat 'Chilero'. Plant Disease 102:421-427, https://doi.org/10.1094/PDIS-1116-1545-RE
Rodríguez-García M. F., J. Huerta-Espino, H. E. Villaseñor-Mir, J. S. SandovalIslas y R. P. Singh (2010) Análisis de virulencia de la roya amarilla (Puccinia striiformis f. sp. tritici) del trigo (Triticum aestivum L.) en los Valles Altos de México. Agrociencia 44:491-502.

Rosewarne G. M., R. P. Singh, J. Huerta-Espino, H. M. William, S. Bouchet, S. Cloutier, H. McFadden and E. S. Lagudah (2006) Leaf tip necrosis molecular markers and B1-proteasome subunits associated with the slow rusting resistance genes Lr46/Yr29. Theoretical and Applied Genetics 112:500-508, https://doi.org/10.1007/ s00122-005-0153-6

Solís M. E., J. Huerta E., P. Pérez H., H. E. Villaseñor M., A. Ramírez R. y M. L. De la Cruz G. (2016) Alondra F2014, nueva variedad de trigo harinero para el Bajío, México. Revista Mexicana de Ciencias Agrícolas 7:1225-1229, https://doi.org/10.29312/remexca.v7i5.248

Villaseñor-Mir H. E., E. Espitia-Rangel, J. Huerta-Espino, A. María-Ramirez, L. Alcalá-Osorio, D. Aguirre-Montoya and R. J. Peña- Bautista (2005) Registration of 'Tlaxcala F2000' wheat. Crop Science 45:424 425, https://doi.org/10.2135/cropsci2005.0425 
